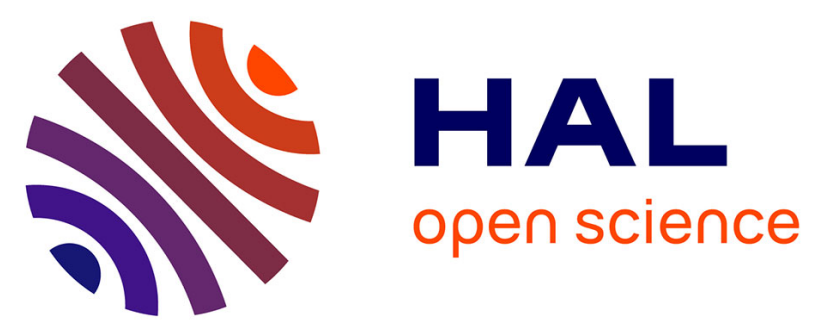

\title{
ECONOMIC EVALUATION OF THE REMOVAL OF POINT OF SALE TOBACCO PROMOTIONAL DISPLAYS IN IRELAND
}

\author{
Casey Quinn, Sarah A Lewis, Richard Edwards, Ann Mcneill
}

\section{- To cite this version:}

Casey Quinn, Sarah A Lewis, Richard Edwards, Ann Mcneill. ECONOMIC EVALUATION OF THE REMOVAL OF POINT OF SALE TOBACCO PROMOTIONAL DISPLAYS IN IRELAND. Tobacco Control, 2010, 20 (2), pp.151. 10.1136/tc.2010.039602 . hal-00586596

\section{HAL Id: hal-00586596 https://hal.science/hal-00586596}

Submitted on 18 Apr 2011

HAL is a multi-disciplinary open access archive for the deposit and dissemination of scientific research documents, whether they are published or not. The documents may come from teaching and research institutions in France or abroad, or from public or private research centers.
L'archive ouverte pluridisciplinaire HAL, est destinée au dépôt et à la diffusion de documents scientifiques de niveau recherche, publiés ou non, émanant des établissements d'enseignement et de recherche français ou étrangers, des laboratoires publics ou privés. 


\title{
ECONOMIC EVALUATION OF THE REMOVAL OF TOBACCO PROMOTIONAL DISPLAYS IN IRELAND
}

\author{
Casey Quinn, PhD \\ Lecturer in Health Economics \\ Division of Primary Care \\ School of Community Health Sciences \\ University of Nottingham, England, UK \\ Sarah Lewis PhD \\ Professor of Medical Statistics \\ UK Centre for Tobacco Control Studies \\ Division of Epidemiology \& Public Health \\ University of Nottingham, England, UK \\ Richard Edwards MD \\ Professor of Public Health \\ Department of Public Health \\ University of Otago \\ Wellington, New Zealand \\ Ann McNeill, PhD \\ Professor of Health Policy \& Promotion \\ UK Centre for Tobacco Control Studies \\ Division of Epidemiology \& Public Health \\ University of Nottingham. England, UK
}

\section{Corresponding author}

Ann McNeill

ann.mcneill@nottingham.ac.uk 


\begin{abstract}
Aim:

To evaluate the short-term economic impact of legislation removing point of sale tobacco promotional displays (i.e. tobacco displays and other point of sale tobacco advertising) in Ireland, implemented July 2009, on cigarette sales across a range of categories of retail outlets.
\end{abstract}

\title{
Methods:
}

Cigarette sales were evaluated using scanning (weekly data since January 2006) and audit data (bimonthly since November 2007) within different retail categories using data sourced from AC Nielsen. Visual inspection and time-series regression techniques were utilized where appropriate to assess changes in sales over time and in relation to the legislation.

\section{Results:}

No change was observed in sales data in any retail category over and above seasonal patterns and an underlying downward trend over time. Similarly, where available data enabled statistical analysis, there was no significant effect in the short term (up to 12 months after implementation) on retail sales of tobacco products, over and above seasonal and long term trends.

\section{Conclusions:}

Recent claims of substantial revenue losses and closures of small retailers as a direct result of the removal of point of sale tobacco promotional displays in Ireland are not borne out by these data. The removal of point of sale displays is aimed at reducing the pernicious effects of tobacco advertising on children and is therefore likely to have an impact on sales over a much more protracted time period. This should enable retailers to adapt over time, perhaps using such regulations as an opportunity to play a role in promoting healthier products in the local community. 


\section{Introduction}

One of the main remaining channels for tobacco marketing, in the advent of legislation prohibiting tobacco advertising, is at the point of sale. [1,2] Point of sale marketing includes displays of tobacco packs and other advertising and promotion at the point of sale or purchase (referred to here as point of sale promotional displays). Research and examination of industry documents have demonstrated how the tobacco industry has increasingly developed and channeled resources into point of sale marketing [3-6], and how point of sale displays have grown in size and prominence in recent years. [7] Research has also demonstrated how point of sale promotional displays influence susceptibility to smoking and smoking uptake among youth. $[8,9]$

Several countries have implemented, or plan to implement, legislation removing point of sale advertising and displays. On 1 July 2009, Ireland removed point of sale tobacco advertising and displays through further provisions of its Public Health (Tobacco) Acts 2002 to 2009. The legislation also prohibited vending machines except in licensed premises and registered clubs (in accordance with Regulations), and required that all persons selling tobacco products by retail had to register with the Office of Tobacco Control (OTC). The legislation was intended to have a long-term public health impact, reducing minors' access to tobacco products, de-normalising smoking and reducing smoking initiation. [10] We have reported separately retailer compliance with the legislation and short term impacts on adolescent and adult smoking attitudes and behavior. [11]

Recently, Irish retailers have claimed that retail cigarette sales have fallen $40 \%$ in the last year, as a result of the legislation. [12] This followed the release of reports purporting to analyse the impact of similar policies internationally, which concluded that removal of point of sale advertising and tobacco displays had an immediate, negative impact upon retail sales in Ireland, both of tobacco products and other products, and affected retailer viability. [13,14] We believe that these reports are severely limited in the scope of their data and their analysis.

We therefore examined the available data on cigarette pack sales from different categories of retailers in Ireland to investigate the impact of implementation of the point of sale legislation.

\section{Methods}

\section{Data}

We used retail sales data collected by AC Nielsen and purchased by the Office of Tobacco Control, Ireland. AC Nielsen's Retail Measurement Service provides data for the confectionery/grocery sector covering: Multiples; Symbol Groups; Forecourts; Tobacco, Sweets and Newsagents (TSNs))/Independent Garages; and Independents (see Table 1 for definitions). These retail channels capture all retail outlets in Ireland except vending machine sales.

Cigarette pack sales data varied between retailer categories with respect to the sample size and sample fraction, time periods and level of aggregation over time. The data came from a census of Multiples (minus the Dunnes retail chain which consists of about 100 retail outlets), a large 
representative sample of Symbols and Forecourt stores, and from a small representative sample of TSNs and Independents. Multiples, Symbols and Forecourt stores provided weekly Electronic Point of Sale (EPOS) information from scanning of tobacco product purchases since January 2006. TSNs and Independents do not collect EPOS data, but provide audit data (where AC Nielsen auditors visit retailers and examine invoices, enter purchase data and look at stocks, validating data collected for a period of the time covered). These audit data were provided in bimonthly (in 8-week or 10-week aggregates) rather than weekly segments and were only available from January 2007. Table 1 gives data on the retail universe and the sampling details and period covered for data on cigarette sales. The number sampled, $n$, gives the total number of stores for each category, for 2009, which is indicative of sampling for all years.

Table 1. Data from retail grocery categories covered by AC Nielsen

\begin{tabular}{|c|c|c|c|c|c|}
\hline \multirow[t]{2}{*}{ Retail category } & \multicolumn{4}{|c|}{$\begin{array}{l}\text { Total number of stores (\% annual } \\
\text { change in number of stores) }\end{array}$} & \multirow[t]{2}{*}{$\begin{array}{l}\text { Coverage and date of } \\
\text { sample for cigarette } \\
\text { sales data }\end{array}$} \\
\hline & 2006 & $2007^{\mathrm{D}}$ & $2008^{c}$ & 2009 & \\
\hline $\begin{array}{l}\text { Multiples (large supermarket } \\
\text { chains e.g. Tesco, Super } \\
\text { Quinn) }\end{array}$ & 292 & $\begin{array}{r}294 \\
0.7 \%\end{array}$ & $\begin{array}{r}322 \\
9.5 \%\end{array}$ & $\begin{array}{r}334 \\
3.7 \%\end{array}$ & $\begin{array}{l}\text { Census EPOS 100\%; } \\
n=334 \text { in } 2009\end{array}$ \\
\hline $\begin{array}{l}\text { Symbols (stores part of a } \\
\text { buying group; owner operated } \\
\text { or part of a franchise e.g. } \\
\text { Centra, Londis, Mace) }\end{array}$ & 1276 & $\begin{array}{r}980 \\
-23.2 \%\end{array}$ & $\begin{array}{r}1,669 \\
70.3 \%\end{array}$ & $\begin{array}{r}1,624 \\
-2.7 \%\end{array}$ & $\begin{array}{l}\text { Sample EPOS; } n=979 \text { in } \\
2009\end{array}$ \\
\hline $\begin{array}{l}\text { Forecourts } \\
\text { (service stations) }\end{array}$ & 148 & $\begin{array}{r}484 \\
227 \%\end{array}$ & $\begin{array}{r}882 \\
82.2 \%\end{array}$ & $\begin{array}{r}925 \\
4.9 \%\end{array}$ & $\begin{array}{l}\text { Sample EPOS; } n=485 \text { in } \\
2009\end{array}$ \\
\hline $\begin{array}{l}\text { TSNs (independent stores and } \\
\text { garages that have at least } 50 \% \\
\text { of their profits from tobacco, } \\
\text { sweets and newspapers) }\end{array}$ & 2,240 & $\begin{array}{l}2,025 \\
-9.6 \%\end{array}$ & $\begin{array}{r}1,381 \\
-31.8 \%\end{array}$ & $\begin{array}{l}1,317 \\
-4.6 \%\end{array}$ & Audit data; n=89 in 2009 \\
\hline $\begin{array}{l}\text { Independents (other } \\
\text { independent stores and } \\
\text { smaller chains not included in } \\
\text { Symbols) }\end{array}$ & 2,739 & $\begin{array}{r}2,303 \\
-15.9 \%\end{array}$ & $\begin{array}{r}1,491 \\
-35.3 \%\end{array}$ & $\begin{array}{r}1,445 \\
-3.1 \%\end{array}$ & Audit data; n=69 in 2009 \\
\hline TOTAL & 6,695 & 6,086 & 5,745 & 5,645 & \\
\hline
\end{tabular}

${ }^{a}$ This category excludes Dunnes Stores which numbered 79 in 2006, and 100 in 2008 and 2009 (data unavailable for 2007)

${ }^{b}$ This figure is affected by the reclassification of some 'Symbols' stores sited on forecourts into the 'Forecourts' category in 2007

${ }^{c}$ This figure is affected by the reclassification of some stores from the 'Independents' and 'TSN' categories to the 'Symbols' and 'Forecourts' categories in 2008. 


\section{Analysis}

We looked at changes in sales of cigarette packs over time. Weekly data from Multiples, Symbols and Forecourts were converted into bi-monthly data for comparison with the available data from TSNs and Independents. Analysis of these data was limited because the data were aggregated into dissimilar blocks (as discussed above, eight to ten weeks depending upon the months which precludes disaggregation informatively into weekly data), and because, once aggregated, too few data points (and hence degrees of freedom) exist for robust methods such as regression to be feasible. Visual inspection is therefore used to comment on the patterns observed.

For the weekly data (available only for Multiples, Symbols and Forecourts), the greater number of data points $(t=232$ weeks) enabled more rigorous analysis to be carried out. Time-series regression techniques were used to determine changes in sales, controlling for seasonality, trading-day and cyclical variation, and secular trends in the data. First-differencing (subtracting the previous week's data from any current week, such that analysis is conducted on change in sales from the previous week) was employed to factor out the secular trend.

The regression equation estimated is as follows:

$$
\begin{aligned}
\left(\text { Sales }_{t}-\text { Sales }_{t-1}\right)= & \beta_{0}+\beta_{1}\left(\text { Sales }_{t-1}-\text { Sales }_{t-2}\right)+\beta_{2}\left(\text { Sales }_{t-2}-\text { Sales }_{t-3}\right) \\
& +\beta_{3} \text { Spring }+\beta_{4} \text { Autumn }+\beta_{5} \text { Winter } \\
& +\beta_{6} \text { FinalWeek }+\beta_{7} \text { FirstWeek }+\beta_{8} \text { POSremove }
\end{aligned}
$$

The reference category in this equation corresponds to summer, weeks preceding the removal of point of sale promotional displays and a week that is neither the final nor the first week of the calendar year. The trend is captured via differencing $\left(\right.$ Sales $_{t}-$ Sales $\left._{t-1}\right)$ and using two lags; time is the weekly trend (time $=1, . ., T$, the end of the series); and seasonality is controlled for (by calendar season), as is the Christmas trading effect ("Final Week" and "First Week" are the last and first calendar weeks of the year, respectively). Finally, the variable POSremove is an indicator for the removal of promotional displays.

Estimation was conducted using Stata SE, version 11. [15] The data were made stationary via differencing, in order that all statistical controls - differencing, seasonal controls, etc. - could be contained with the regression model parameters. [16] The number of lags was selected by comparing Autocorrelation and Partial Autocorrelation Functions. Prior testing for structural breaks in the data was performed, however none were found. Finally, tests for unit roots were negative and the data appeared to be trend-stationary. The data were sufficiently stationary and the model appeared satisfactorily specified for testing whether there was an effect of the legislation on retail cigarette sales.

\section{Results}


Prior to the implementation of the point of sale legislation, between 2006 and 2008, the data shown in Table 1 illustrate that the proportion of Multiples, Symbols and Forecourts in Ireland increased, at the expense of Independents and TSNs which were showing declines year on year even when accounting for some reorganisation of retail outlets within the categories.

Figure 1 shows the series of bi-monthly aggregated data that include TSNs and Independents; the vertical reference line indicates the date of the implementation of the legislation.

\section{Figure 1 about here}

In Figure 1, "Total" gives the sum of the five retail categories. Upon visual inspection, one can observe two key characteristics of the series. First, the data are seasonal, with significant boosts in sales during the summer months. This corresponds in particular with seasonal tourism, which has also declined in recent years. [17]. There is also an apparent time trend in nearly all of the series: specifically, cigarette-pack sales are declining. These data also show that the bulk of the sales is coming from the Symbols group with the Forecourts second, despite the latter category having a smaller number of stores than the other categories except Multiples. Sales in Multiples are lowest although they show less of a decline and appear to surpass sales in Independents at the end of the series.

Figure 2 illustrates the weekly data for Multiples, Symbol Groups and Forecourts - all of which have EPOS weekly data collection; again the vertical reference lines indicate the date of the implementation of the legislation.

\section{Figure 2 about here}

In Figure 2, "Total" gives the total of the three retail categories shown: Forecourts, Symbols, Multiples. Visual inspection of these graphs also show a clear decline in cigarette sales since June 2006, overall and in each of the retail categories, although less pronounced in the Multiples. Seasonal effects can again be observed in the data as well as sharp spikes in late December. The end-of-year spike/trough in sales is also larger in magnitude than the seasonal effects. Seasonality is more apparent in Figure 1 than in Figure 2 because of the aggregation of weeks, which reduces the impact of the spike in sales at the end of the year.

Table 2 contains the results for variable of interest from the regression analysis. Separate regression models were run for Multiples, Symbols, Forecourts and Total Tracked Scans.

Table 2. Time-series Regression Results for First-Differenced Weekly Unit Sales

\begin{tabular}{|l|r|r|r|r|}
\hline \multicolumn{1}{|c|}{ Series } & $\begin{array}{c}\text { PoS display } \\
\text { removal } \\
\text { coefficient }\end{array}$ & $p$-value & \multicolumn{1}{c|}{$\begin{array}{c}\text { Lower 95\% } \\
\mathrm{Cl}\end{array}$} & \multicolumn{1}{c|}{$\begin{array}{c}\text { Upper 95\% } \\
\mathrm{Cl}\end{array}$} \\
\hline Total & $-5,848$ & 0.616 & $-28,798$ & $17,102$. \\
\hline Multiples & $-1,045$ & 0.623 & $--5,225$. & 3,134 \\
\hline Symbols & $-3,909$ & 0.547 & $-16,686$ & 8,868 \\
\hline
\end{tabular}




\begin{abstract}
\begin{tabular}{|l|r|r|r|r|}
\hline Forecourts & -767 & 0.838 & $-8,140$ & 6,604 \\
\hline
\end{tabular}
Notes: The estimate "PoS display removal coefficient" corresponds to POSremove in Equation (1) and gives the estimate of the impact (change in weekly unit sales) of removing point of sale displays after controlling for all other variables given in the equation. Control variables from the regression equation (1) are not included, but can be obtained from the authors.
\end{abstract}

After controlling for seasonality, the secular trend and end-of-year trading-day effects seen in Figure 2, there is no evidence that the removal of point of sale displays had an effect on cigarette sales. In addition, the coefficients are small relative to the means in each series: the effect of the first and last weeks of the calendar year are statistically significant and up to several hundred times greater in impact; the seasonal effects were statistically significant and with similarly larger impact. In the 12 months following the removal of point of sale displays, no impact on retail sales of cigarette packs was observed that can be attributed to the policy.

\title{
Discussion
}

This is the first study in the peer reviewed literature to examine the economic impact of national legislation removing point of sale tobacco promotional displays on the retail sector. No statistically significant change in cigarette pack sales was observed following the implementation of the legislation for three main categories of retailer: Multiples, Symbols and Forecourts, over and above seasonal and underlying trends. Visual inspection of the available cigarette sales data for these channels and the Independents and TSNs also indicated seasonal patterns and an underlying downward trend; no changes were observed following the legislation, over and above these trends across all the different categories. These findings contradict recent reports $[13,14]$ that sales have rapidly decreased and are being lost since the removal of point of sale promotional displays and secondly, that this decline can be attributed to the policy. In contrast, our analysis indicates that any decline is almost surely a function of broader phenomena, such as the global recession and secular trends that have seen an increase in some retail categories at the expense of the Independent sector. The seasonality observed in the Irish sales data has been found elsewhere, with greater sales around the Christmas season and year-end [19] and during the summer months. [20]

This study has several limitations. TSN and Independents' data were not available at the level of disaggregation suitable for time-series regression and the effect of the legislation on cigarette sales in those store categories could not therefore be tested with the same rigour as data from the other retail categories. Another limitation was that the proportion sampled for the Independents and TSNs was much smaller than that of the other retail outlets, so there is more uncertainty about the data on sales trends from these store types. Other measures introduced alongside the removal of point of sale promotional displays, such as the retailer registry and removal of vending machines, may be having an impact although we believe this is very unlikely given the low cost of registration (50 Euro) and the small contribution that vending machines play in overall sales (although larger for children). Finally, only short-term impacts of the legislation were assessed (up to one year after implementation), and it is possible that results would be different if followed up after a longer spell post-legislation.

The downward trend in cigarette sales over the years studied is likely to be a result of a number of different factors. Some substitution for cigarette packs has been observed with hand-rolling 
tobacco [18], as well as illicit (smuggled, bootlegged or counterfeit) tobacco, over the last decade. Hand-rolled tobacco sales are a small proportion of the overall market (currently around $5 \%,[18])$ and would still benefit retailers when purchased legally. Other contributory factors to the downward trend may be implementation of other tobacco control strategies. For example, Ireland introduced smoke free work and public places in 2004, annual tax increases on tobacco products (averaging 0.39 Euro increase annually over the last four years), and a ban on packs of ten cigarettes at the end of May 2007.

The point of sale legislation was introduced during a global recession. The figures for retail grocery categories shown in Table 1 indicate that the recession was affecting the various categories of retail grocery outlets in different ways. The decline in the small retailer sector has been observed elsewhere [21]. Other commentators have reported that the number of retail outlets in the grocery sector in Ireland declined overall by 54.3\% between 1977 to 2006, with most of this decline being in the smaller Independent shops (eg decline in Independents 63.4\%, Symbols $18.8 \%$, whereas Multiples increased by 170\%). [21] The expansion of some retail categories at the expense of smaller independent stores probably reflects changes in behavior of shoppers due to greater price competition and enhanced and broader ranges of products, particularly during a recession. [22] The impact on closures of independent traders such as butchers, bakers and general store has been documented elsewhere. [23]. Historically larger chains have a stronger focus on key cities such as Dublin, Belfast, Derry, Cork and Galway, where they are also better-able to withstand rent-inflation than Independents [24], although they are opening increasingly in smaller centres also. These phenomena precede the removal of tobacco point of sale promotional displays by several years and are part of wider forces and trends and cannot be attributed to the legislation. Nevertheless, as cigarette sales may be affected by consumer trends differently in other countries, where the retail sector market might have different categories affected in other ways, the findings here are not necessarily generalisable to other countries.

The argument has also been made, particularly by retail and tobacco industry groups, that nontobacco sales are part of the losses faced by retailers, following decreased footfall as a result of decreased tobacco sales. However this would be a consideration if, and only if, tobacco sales themselves were significantly affected by the tobacco display removal, which we did not find was the case. Available data on non-tobacco sales (not presented here, but also from AC Nielsen) show a similar annual decline in overall sales that precedes the promotional display removal and appeared unaffected by the policyimplementation. The conclusion remains that small and independent retailers are facing a broader and longer-term decline in sales generally which is most likely due to other causes. .

Trends observed elsewhere of sales and customers moving away from smaller independent retailers to multiple chains have prompted some analysts to comment on the attributes and selling points that such independents have, such as location and speed of service. [25] We argue that the overall long-running decline in cigarette sales across the retail sector will require that all types of retailers need to adapt. Adaptation to consumer demand is one of the features of the retail sector. One way in which small independent retailers could adapt is to take the opportunity to be responsive to their local communities, for example by being at the forefront of health promoting consumer marketing and playing a leading role in their local communities in promoting healthy 
behaviours. Retailers could make a virtue out of having cigarettes out of sight, as this may make it more difficult for children to request cigarettes [11], but they could also make available and proactively signpost cessation support to adults. In some countries nicotine replacement therapies (a much less harmful form of nicotine intake) can be purchased on general sale (ie in nonpharmacies as well as pharmacies) and these could be promoted instead of cigarettes to encourage smokers to quit.

Contemporaneous research [11] carried out in Ireland has demonstrated that retailers were quickly compliant with the regulations which were also largely effective at removing cigarette and tobacco packs from view. Recall of seeing cigarette and tobacco displays decreased significantly in adult and youth samples, with the observed drop being greater among youth than adults. There were also promising signs that the law was effective at de-normalising smoking, at least in the short term, as evidenced, inter alia, by decreases in the proportion of children thinking that more than $20 \%$ of their age group smoked. These findings suggest that despite the evidence from this analysis of a minimal effect on tobacco sales, the removal of point of sale displays are likely to have a longer term impact on sales as the impact on denormalisation and reduced initiation among youth take effect.

In conclusion, this paper indicates that the removal of point of sale promotional displays did not have an immediate impact on cigarette pack sales when underlying trends and seasonality in the data are taken into effect, nor was there an impact in on retail closures. The disastrous effect on retailers predicted by opponents of the removal of point of sales displays have not materialised. Cigarette pack sales in Ireland are continuing to show an overall downward trend. As it is anticipated that point of sale policies are likely to have an effect over a much longer time period, a replication of this research in a few years time is recommended, to assess if the long term decline in cigarette pack sales has been further increased by the removal of point of sale tobacco promotional displays.

\section{Funding}

We are grateful for funding from the Office of Tobacco Control (OTC) Ireland, Cancer Research UK, the Irish Cancer Society (ICS), and ASH New Zealand to support this research and analysis.

\section{Acknowledgements}

We are grateful to the Office of Tobacco Control for providing the A C Nielsen data and to Marie Killeen and Shane Allwright who commented on an earlier draft of this manuscript.

The Corresponding Author has the right to grant on behalf of all authors and does grant on behalf of all authors, an exclusive licence (or non-exclusive for government employees) on a worldwide basis to the BMJ Publishing Group Ltd and its Licensees to permit this article (if accepted) to be published in Tobacco Control and any other BMJPGL products to exploit all subsidiary rights, as set out in our licence (http://group.bmj.com/products/journals/instructions-for-authors/licenceforms). 


\section{What is already known}

- Point of sale tobacco promotional displays are a major remaining channel of tobacco promotion following tobacco advertising bans

- Governments are introducing policies to remove point of sale promotional displays to protect children from tobacco advertising

- There is a dearth of research on the impact of removing point of sale tobacco promotional displays

\section{What this paper adds}

- Removal of the point of sale tobacco promotional displays had no short term impact (one year post ban) on cigarette pack sales

- There is a general downward trend in cigarette pack sales which preceded the point of sale policy by several years, which is due to a number of other factors

- Impact on sales will likely take effect over a much longer period allowing retailers to adapt over time 
Confidential draft - please do not cite or copy

\section{Figures}

Figure 1. Trends in tobacco packs sold bi-monthly across different retail outlets [source: AC Nielsen]

Figure 2. Trends in tobacco packs sold weekly across Multiples, Forecourts and Symbols and total EPOS scans [source: AC Nielsen]

Footnote for Figure 2: different scales are used on the y axes because of the different volumes of sales in the different retail categories. 


\section{References}

1. National Cancer Institute. The Role of the Media in Promoting and Reducing Tobacco Use. Tobacco Control Monograph No. 19. Bethesda, MD: U.S. Department of Health and Human Services, National Institutes of Health, National Cancer Institute. NIH Pub. No. 07-6242, June 2008.

2. Dewhirst T. POP goes the power wall? Taking aim at tobacco promotional strategies utilized at retail. Tobacco Control 2004;13:209-10.

3. Wakefield MA, Terry-McElrath YM, Chaloupka FJ, Barker DC, Slater SJ, Clark PI, Giovino GA. Tobacco industry marketing at point of purchase after the 1998 MSA Billboard Advertising Ban. American Journal of Public Health 2002;92:937-40.

4. Lavack AM, Toth G. Tobacco point-of-purchase promotion: examining tobacco industry documents. Tobacco Control 2006;15:377-384.

5. Pollay RW. More than meets the eye: on the importance of cigarette retail merchandising. Tobacco Control 2007;16:270-4.

6. Rooke C, Cheeseman H, Dockrell M, Millward D, Sandford A. Tobacco point-of-sale (PoS) displays in England: a snapshot survey of current practices. Tob Control online first doi:10.1136/tc.2009.034447.

7. MacGregor J. Tobacco Advertising at Point of Sale (Report to ASH) MacGregor Consulting Ltd., August 2008.

8. Paynter J, Edwards R. The impact of tobacco promotion at the point of sale: A systematic review. Nic Tob Res 2009;11:25-35.

9. Henriksen L, Schleicher NC, Feighery EC, Fortmann SP. A longitudinal study of exposure to retail cigarette advertising and smoking initiation. Paediatrics 2010;126:232-8. Epub 2010 Jul 19.

10. Office of Tobacco Control. Background information on legislation. See http://www.otc.ie/rg-background.asp

11. McNeill A, Lewis S, Quinn S, Clancy L, Mulcahy M, Hastings G, Edwards R. Evaluation of the removal of point of sale tobacco promotional displays in Ireland. Manuscript submitted for publication.

12. Carty E. Cigarette sales see 40pc drop in a year. Evening Herald. 1 July 2010.

13. Basham, P. 2010. Canada's ruinous tobacco display ban: economic and public health lessons. IEA Discussion Paper 29. Institute of Economic Affairs, London.

14. Lilico, A. 2009. The Impacts of Restrictions on the Display of Tobacco Products. A Supplemental Report by Europe. Economics. Europe Economics

15. StataCorp. 2009. Stata: Release 11. Statistical Software. College Station, TX: StataCorp LP.

16. Hamilton, J.D. 1994. Time Series Analysis. Princeton University Press, Princeton, NJ.

17. Central Statistics Office. 2010. Tourism and Travel 2009. Central Statistics Office, Ireland.

18. Revenue. Statistical Report $2008 . \quad$ Available at: http://www.revenue.ie/en/about/publications/statistical/archive/2008/

19. Chandra, S., Chaloupka. F.J. 2003. Seasonality in cigarette sales: patterns and implications for tobacco control. Tobacco Control, 12: 105-107.

20. Wellman, R.J., DiFranza, J.R. 2003. Seasonality in onset of youth smoking parallels seasonality in cigarette sales. Tobacco Control, 12: 339 
21. Power, J. 2010. The economic and financial significance of the 'local shop'. Report prepared for RGDATA .Jim Power Economics.

22. Mintel 2010. See http://www.just-style.com/market-research/expansion-of-non-foodlines-in-supermarkets-ireland-march-2010 id89451.aspx http://oxygen.mintel.com/sinatra/oxygen/display/id=518239

23. MacGilivray, A., Simms, A., Drury, J., Oram. J. 2002. Ghost Town Britain. London: New Economics Foundation.

24. InterTradeIreland 2000. Clothing and footwear. An Ireland Retail Perspective. http://www.intertradeireland.com/module.cfm/opt/29/area/Publications/page/Publications/ down/yes/id/57

25. Baron, S., Harris, K., Leaver, D. and Oldfield, B. 2001. Beyond convenience: the future for independent food and grocery retailers in the UK. International Review of Retail, Distribution and Consumer Research, 11(4): 395-414. 

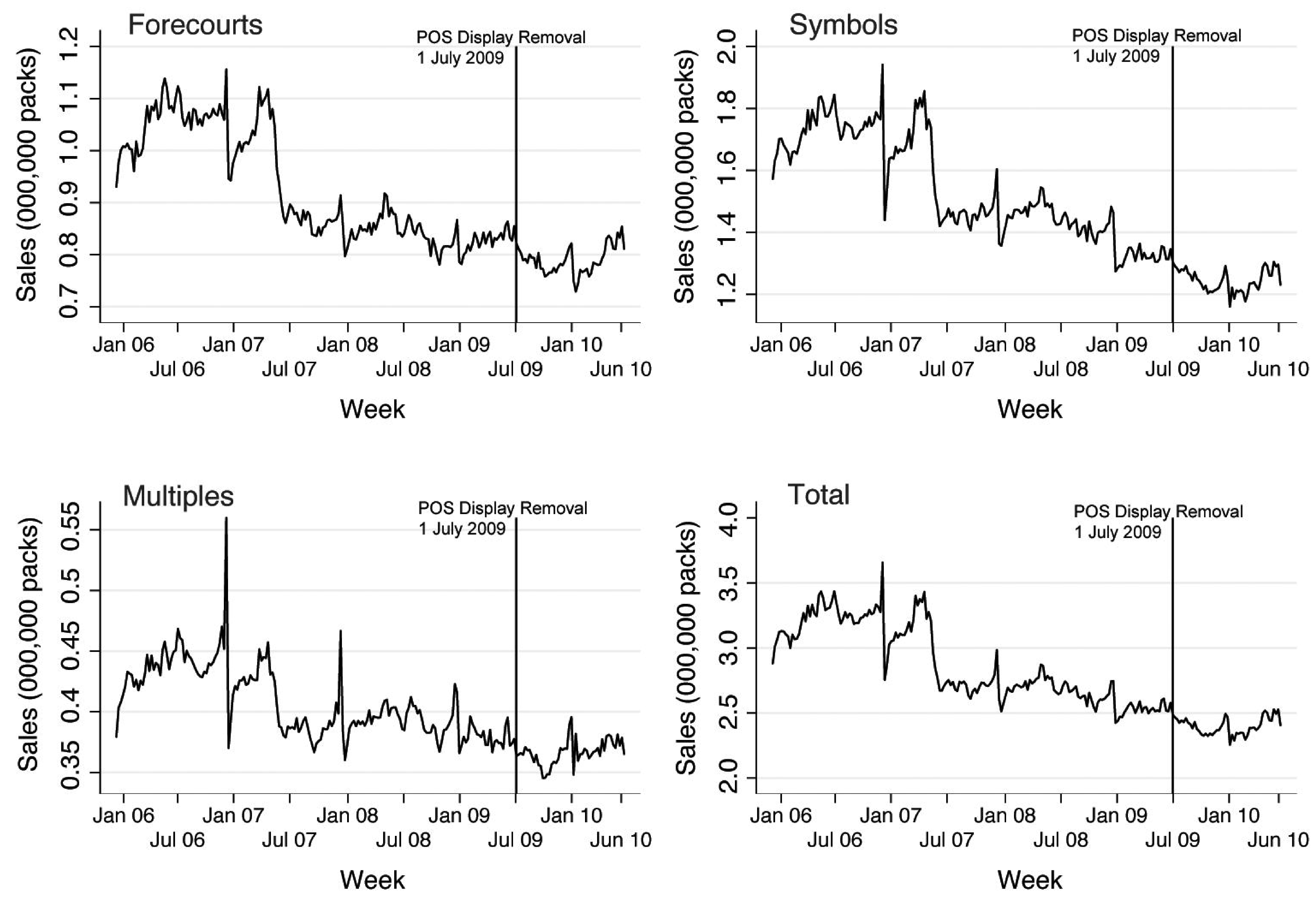